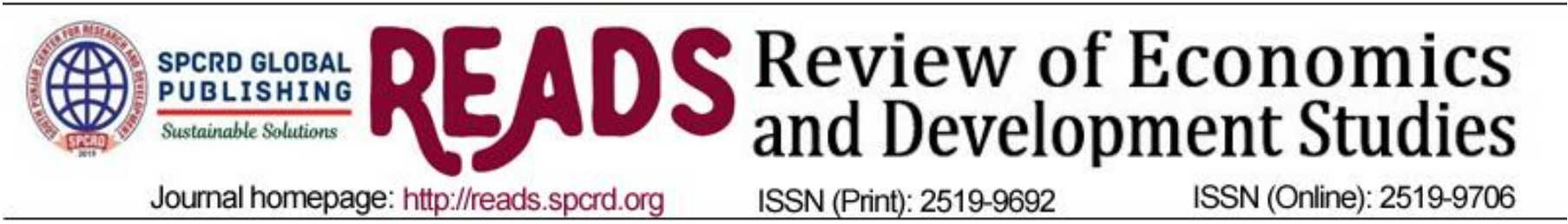

\section{Long-Run Relationship Between Economic Development and International Tourism in Pakistan}

\author{
${ }^{a}$ Muhammad Asif Khan, ${ }^{b}$ Ghulam Mujtaba Chaudhary, ${ }^{c}$ Khalid Latif, ${ }^{d}$ Naveed Ahmed \\ ${ }^{a}$ Faculty of Management Sciences, University of Kotli Azad Jammu and Kashmir, Kotli, Pakistan \\ Email: khanasif82@uokajk.edu.pk \\ ${ }^{\mathrm{b}}$ Faculty of Management Sciences, University of Kotli Azad Jammu and Kashmir, Kotli, Pakistan \\ Email: adfuajk@yahoo.com \\ ${ }^{c}$ College of Commerce, Government College University Faisalabad, Pakistan \\ Email: khalidlatif@gcuf.edu.pk \\ d Lecturer IMS, University of Agriculture, Sub Campus Toba Tek Singh, Pakistan; \\ Email:n.ahmed@uaf.edu.pk
}

\begin{tabular}{l}
\hline ARTICLE DETAILS \\
\hline History: \\
Accepted: 12 April 2020 \\
Available Online: 15 June 2020 \\
\hline Keywords: \\
Economic Development, Financial \\
Development, Stock Market \\
Development, Tourism, \\
Cointegration
\end{tabular}

JEL Classification:

O1, Z32, Z33, Z38, L83

DOI: $10.47067 /$ reads.v6i2.199

\begin{abstract}
This article examines the link between economic development and international tourism in the context of Pakistan. The study uses Autoregressive Distributed Lag tests (ARDL) for the long-term relationship; the short-term relationship is examined with Error Correction model, and the VECM-Granger causality to determine the direction of the causal flow. The study uses annual data from the CEIC and World Bank databases for the period 1990-2017. The novelty stems from the perspective that there is no formal evidence on long-run dynamics between economic development indicators and international tourism from Pakistan. It contributes to the existing literature on this vital phenomenon. The empirical results document the long-term and short-term association between the variables. We also find a two-way causal flow between economic development and tourism. In addition, it offers policy implications for focusing on three economic dimensions, e.g. economic development, financial development, and stock market development, which subsequently attracts international tourism. Intuitively, promulgates National culture and image across borders and strengthens the National Treasury as well.
\end{abstract}

(C) 2020 The authors. Published by SPCRD Global Publishing. This is an open access article under the Creative Commons Attribution-NonCommercial 4.0

Corresponding author's email address: khalidlatif@gcuf.edu.pk

\section{Introduction}

The consideration of tourism and its economic consequences have been concentrated in the last decades all over the world. Pakistan is one of the few blessed countries with diverse geographic and ethnic diversity and offers adventure tourism, ecotourism, spiritual tourism, heritage tourism, and sports tourism. Adventure tourism includes unique mountains, valleys, and glaciers. Silk Road. 
Trucking Jeep Safari, Helicopter Safari, Flight Safari, and Train Safari. Ecological tourism consists of the Ayubia National Park. Whitewater sports, historic sites of wetlands and salt marshes, a forest of sea turtles and mangroves, bird watching along the Karakoram highway. Brown is a level of the blind dolphin of Deosai and Indus. Mental tourism reflects Islam. Sikhism Buddhism and Hinduism. The sightseeing tour included the tomb of Tunkdi Makris (Thatta), Sha Ji Han Mosque. Strong Rawat, Fort Lotus, Civilization of the Indus Valley. Mehrgara, the civilization of Gandhara, the treasure of Mughal and Uch Sharif. Meanwhile, sports tourism counts to white water rafting. Climbing, Shandor Polo Festival, golf, boar hunting, Buzkashi, mountain biking, and fishing.

According to Travel and Tourism Competitiveness Report (WEF, 2017) "the direct contribution of travel and tourism to Pakistan's GDP in 2015 was \$ 3.1 million, constituting 2.8\% of total GDP, and by 2025, the government predicts tourism will contribute $\$ 9.5$ billion to the Pakistani economy." Economic expansion is essential for tourism development in Pakistan and tourism and drives economic growth in the short term (Khalil, Kakar, \& Malik, 2007). Malik, Chaudhry, Sheikh, and Farooqi (2010), signify a unidirectional casual and long-run association of tourism and economic growth.

Figure 1 graphically presents the natural logarithm of revenue received from the international tourists in Pakistan from 1990 to 2017. The climax was observed in 2011, and the lowest point was 1999. The overall pattern shows a positive trend in tourism receipts. A surge is noticed from 2001 to 2008; however, after 2011 the revenue has surprisingly declined. This may be due to the terrorism and unstable economic conditions prevailing in the country.

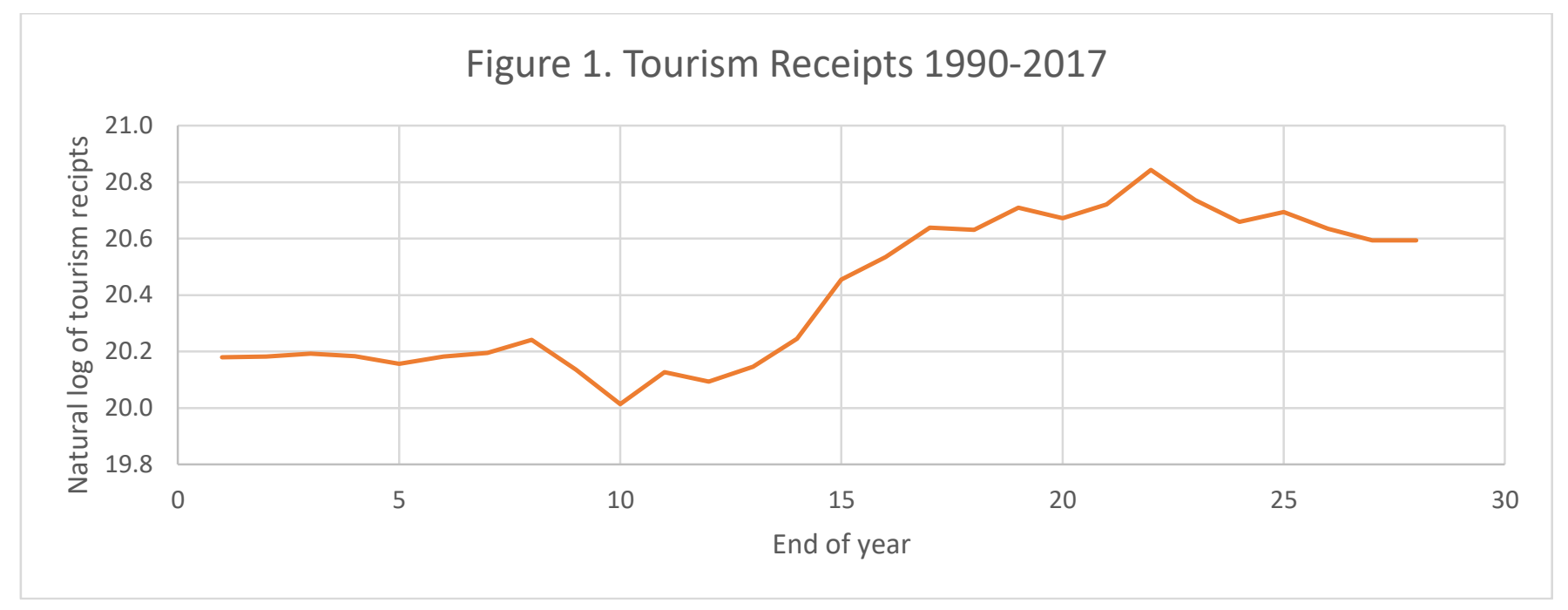

Source: World Bank Development Indicators, and CEIC

Similarly, Figure 2 depicts the number of tourists arrived in Pakistan from 1990 to 2017 on a yearly basis. The pattern somehow resembles that shown in Figure 1. The higher tourists arrive in 2011 and the lowest in 1996. Since 2003, the arrivals have greatly increased until 2006, followed by a slight decline in a coming couple of years. The overall arrivals have shown positive trends, which is lucrative for Pakistan. 
Figure 2. Arrival of number of Tourists to Pakistan 1990-2017

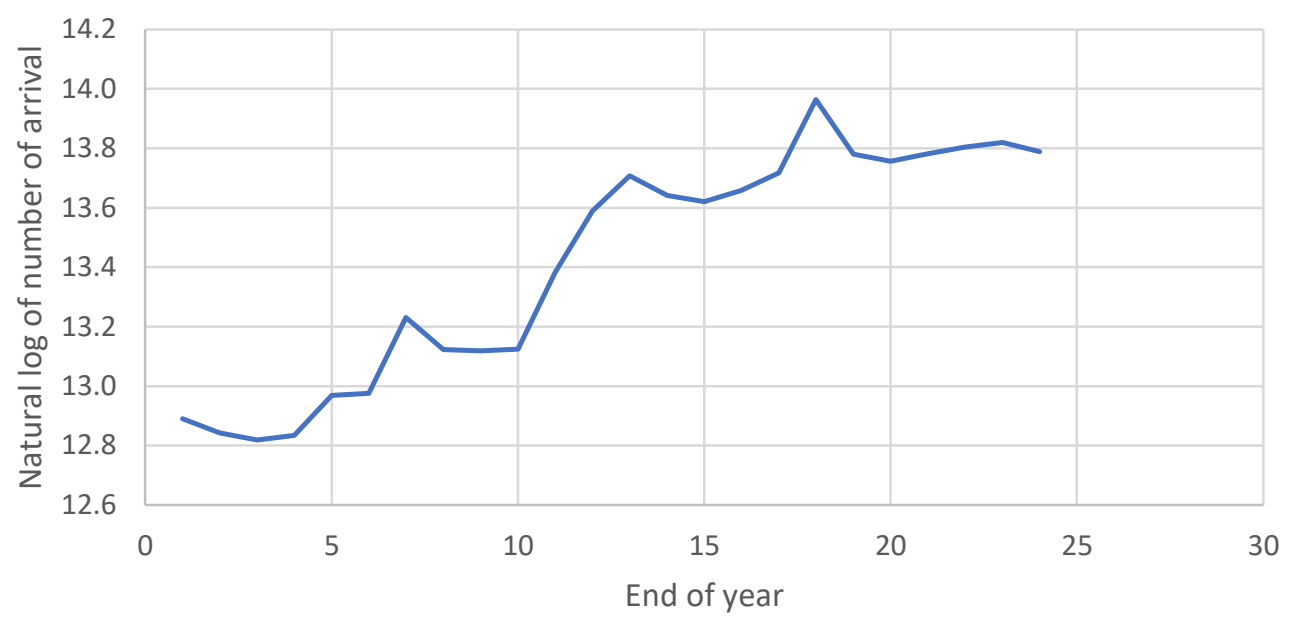

Source: World Bank Development Indicators, and CEIC

Tourism plays a significant role in economic development, particularly with regard to monetary policy and the promotion of national culture around the world. Tourism raises the standard of living of the citizens of the respective country Hrubcova, Loster, and Obergruber (2016). The contribution of tourism to the economic development of Pakistan is remarkable. Therefore, this study is rationally directed to investigate cointegration between economic development and international tourism using the robust ARDL-bounds approach and the Vector Error Correction Granger causality estimators.

The study contributes to the existing knowledge about this important phenomenon of combining economic development and international tourism in the context of Pakistan. We witness the contribution of economic development indicators as useful determinants of in attracting tourists to the country. The empirical findings suggest policymakers and concerned authorities consider a wide range of economic development indicators, rather focusing only on per capita GDP, for the effective and efficient contribution of tourism in the National economy.

Rest of work is organized as follows; Section, 2 reviews the literature. The methodology is explained in section 3. Empirical results are discussed in section 4, and section 5 concludes the study.

\section{Literature review}

This section provides the empirical literature relevant to the nexus of economic development and tourism.

\subsection{Tourism and Economic Development}

According to Hrubcova et al. (2016), tourism has become a relevant sector of the national economy with viable and sustainable economic development options. The authors argue that although there are numerous obstacles in the way, nevertheless, tourism raises the standards of living and negative impacts of tourism such as redistribution of tourism income must be rationalized. Sinclair (1998), highlights tourism supply as key to success, these factors include tour operators, transportation, travel agents, accommodation and cross country integration. Kennell (2016), claims tourism is a key factor in economic growth. The empirical results of impact of tourism in explaining economic growth of Spain, confirm the economic growth of the country determined by tourism (Balaguer \& CantavellaJorda, 2002). The study infers that tourism revenue if positively used, promotes economic activities and tourists activities in particular. Milne and Ateljevic (2001), rather emphasize the need to develop a more 


\section{Review of Economics and Development Studies, Vol. 6 (2) 2020, 229-244}

rigorous understanding of the evolving tourism industry and the way it influences the economic development, this also advocates the role of expanding the network of information and communication technologies.

Liu (2003), critically reviews the tourism literature and its nexus with sustainable economic development and argues that it has become indispensable to incorporate an interdisciplinary approach to have more scientific tourism research. He identifies following six issues to be addressed that are often overlooked: i) the role of tourism demand, ii) the nature of tourism resources, iii) the need of intra-generational equity, iv) the role of tourism in promoting socio-cultural progress, v) measuring sustainability, and vi) shaping sustainable development. Akama and Kieti (2007), study the sustainable tourism as a tool for socio-economic development in Kenya, finds that administration of tourism industry is crucial and with greater external control, the tourism industry appears to be least effective in assuring socio-economic development. The evidence of tourism and economic growth from rich and poor countries, documents that in both type of countries economic consequences of tourism inflow are notable (Sequeira \& Macas Nunes, 2008). Faber and Gaubert (2016), find tourism contributes significantly and largely in economic gains in the case of Mexico. However, this contribution is more obvious in high tourist region.

$\mathrm{Du}$, Lew, and $\mathrm{Ng}$ (2016) argue that the role of tourism for long-term economic growth is built on its role as an integral part of wider development. Zhang and Gao (2016)_examine the power of international tourism in driving Chinese economic progress, and show find a long-run causal flow. Qian, Sasaki, Shivakoti, and Zhang (2016), identify that in China tourism's contribution in economic development is sensitive to governance system, community-based tourism yields greater economic, ecological and social benefits compared with lease operational tourism. There exists a bidirectional relationship between tourism and economic growth, both in short and medium term, however long-run association depends on economic conditions (Antonakakis, Dragouni, Eeckels, \& Filis, 2016).

Srinivasan and Kalaivani (2016)_use panel cointegration and generalized methods of moments method for estimation, and state that there is no long-term relationship between tourism and economic growth in the Asia-Pacific. Nevertheless, the study reports a short-term relationship between the two. Khalil et al. (2007)_indicate that tourism's short-term impact on Pakistan's economic development through an error correction model and a causality analysis shows that there is a short-term link between tourism retention and economic expansion. Malik et al. (2010) examine the cointegration and causal link between tourism and economic growth in Pakistan in the period 1972-2007. The results show a long-term unidirectional causal composition of tourists on GDP. Hye and Khan (2013)_employ Johansen Jeselius along with ARDL approach and observe a long-term relationship between tourism income and economic growth in Pakistan from 1971 to 2008.

Conclusion of empirical literature reviewed in above section reveals that firstly, there is handsome literate available on nexus among tourism and economic development that is unidirectional in nature explored the impact of tourism on economic development and growth, see for example (Akama \& Kieti, 2007; Antonakakis et al., 2016; Balaguer \& Cantavella-Jorda, 2002; Faber \& Gaubert, 2016). Secondly, in the context of Pakistan, this association is least focused so far. We find that some studies use the data until 2008 to investigate the impact of tourism on Pakistan's economic growth (Hye \& Khan, 2013; Khalil et al., 2007) and a lot more has happened since after 2005 devastating earthquake in the Northern region of Pakistan and Kashmir. Similarly, Khalil et al. (2007), use the 1972-2007 data to investigate this connection. Thirdly, past literature shows that tourism's contribution 
is significant and positive relatively in developed countries and least in underdeveloped (Sequeira \& Macas Nunes, 2008). Therefore, this study seeks to answer this question to examine the long and shortrun connection within economic development and international tourism and the direction of causality in the context of Pakistan.

\section{Methodology}

Data sources, measurement of variables, selection of research model and concurrent tests are elementary parts of this section.

\subsection{Data and Measurement of Variables}

This study utilizes annual data from CEIC and World Bank for 1990-2017. The dependent variable international tourism is measured as the natural logarithm of receipts from tourists, and the number of arrival on a yearly basis (Culiuc, 2014). Economic development is captured by three indicators i) domestic credit to privates sector as ratio to GDP (Azeem, Aziz, \& Jadoon, 2015), i) per capita GDP Jebran, Abdullah, Iqbal, and Ullah (2016), iii) market capitalization as to GDP (Azeem et al., 2015; Ullah \& Wizarat, 2016). Consistent with the stream of literature we include the real effective exchange rate (PKR to USD) as an important control for tourism because fluctuations in the real exchange rate of destination country greatly influence the tourism inflows Culiuc (2014).

\subsection{Stationarity Testing}

Prior to test integration order, we determine optimal lag using Akaike information criteria, which suggests two lags are appropriate for estimation. Then we apply Dickey and Fuller (1979), and Dickey and Fuller (1981) ADF tests to determine integration order using equation (1).

$$
\Delta Y_{t}=\alpha_{0}+\rho_{1} Y_{t-1}+\sum_{j=1}^{p} \Delta Y_{t-j}+\epsilon_{t}(1)
$$

Where, $\Delta Y_{t}$ is cha ange in variable $Y$ over time t. $Y_{t-1}$ is lagged value of variable $Y, \alpha_{0}$ and $\rho_{1}$ are the coefficients of estimations, and $\epsilon$ is error-term, $p$ represents maximum lag length. The null hypothesis assumes a unit root in a particular series against the alternative that assumes otherwise. While comparing t-statistics against typical DF critical values, Null hypothesis is accepted when captured t-stat exceeds DF critical value, otherwise, it will be rejected and alternative hypotheses accepted.

\subsection{ARDL Bounds Test of Cointegration}

Cointegration is referred as a linear stationary grouping between two or more non-stationary variables, which is we interpret as the variables are having long-run equilibrium bonding (Engle \& Granger, 1987). Some scholars argue that it is vital to determine cointegration in time series analysis in response to policy reforms, whether reforms account for what was anticipated (Breitung, 2001; Dritsakis, 2004; Johansen, 1991; MacKinnon, Haug, \& Michelis, 1999). The seminal Autoregressive Distributed Lag Model, denoted as ARDL (Pesaran \& Shin, 1998) with extended bounds testing (Pesaran, Shin, \& Smith, 2001) attribute for cointegration has achieved tremendous momentum particularly due to embedded features of producing efficient estimation in case of mixed integration order [I(1) and I(o)]. Further, this methodology delivers best estimates when the sample size is relatively small (Haug, 2002; Pesaran \& Shin, 1998). Nisha (2017), Sharif and Raza (2016), Ullah and Wizarat (2016), Jebran et al. (2016) and many others have applied this robust model to investigate long-run equilibrium relationship among focused variables of respective studies. 
The ARDL regression equation for theoretical relationship among the indicators can be expressed as;

$$
\begin{aligned}
T R 1_{t}= & \beta_{0}+\beta_{1} F D_{t}+\beta_{2} E D_{t}+\beta_{3} S M_{t}+\beta_{4} E R_{t}+\sum_{t-1}^{q} \varphi_{T R} \triangle T R_{t-1}+\sum_{t-1}^{q} \varphi_{F D} \triangle D F_{t-1} \\
& +\sum_{t-1}^{q} \varphi_{S M} \Delta S M_{t-1}+\sum_{t-1}^{q} \varphi_{E R} \Delta E R_{t-1}+\sum_{t-1}^{q} \varphi_{T R} \Delta T R_{t-1}+\mu_{t} \text { (2) } \\
T R 2_{t}= & \beta_{0}+\beta_{1} F D_{t}+\beta_{2} E D_{t}+\beta_{3} S M_{t}+\beta_{4} E R_{t}+\sum_{t-1}^{q} \varphi_{T R} \triangle T R_{t-1}+\sum_{t-1}^{q} \varphi_{F D} \Delta F D_{t-1}+ \\
& +\sum_{t-1}^{q} \varphi_{S M} \triangle S M_{t-1}+\sum_{t-1}^{q} \varphi_{E R} \triangle E R_{t-1}+\sum_{t-1}^{q} \varphi_{T R} \triangle T R_{t-1}+\mu_{t}(3)
\end{aligned}
$$

Here, TR1 and TR2 signify the natural log of international tourism - number of arrivals, and receipts in US dollar respectively. FD, financial development, ED, economic development, SM, stock market development, ER, real effective exchange rate as to US dollar, $\Delta$ is the difference operator, $q$ is optimum number of lags, $\beta, \varphi$ and $\omega$ are respective coefficients. $H_{0}: \varphi_{T R}=\varphi_{F D}=\varphi_{E D}=\varphi_{S M}=$ $\varphi_{E R}=0$ assumes that no long-run relationship holds among variables. $H_{1}: \omega_{T R} \neq \omega_{F D} \neq \omega_{E D} \neq$ $\omega_{S M} \neq \omega_{E R} \neq 0$, implies that long-run relationship holds.

\subsection{Error Correction Model}

The study uses the Error Correction Model (ECM) in addition to the ARDL bound test to examine cointegration between variables. The long-term relationship applies only if the ECT coefficient carries negarivley significatn sign. The ECT coefficient measures the rate at which the system corrects the disequilibrium of the previous period. We use the following equation:

$$
\begin{aligned}
\Delta T R_{t}= & \lambda_{0}+\lambda_{1} \sum_{i=1}^{q} \Delta F D_{t-1}+\lambda_{2} \sum_{i=1}^{q} \Delta E D_{t-1}+\lambda_{3} \sum_{i=1}^{q} \Delta S M_{t-1}+\lambda_{4} \sum_{i=1}^{q} \triangle E R_{t-1}+\eta E C T_{t-1} \\
& +\mu_{t}(4)
\end{aligned}
$$

Where "ECT $\mathrm{t}_{\mathrm{t}-1}$ " denotes the error correction term and Coefficients $\lambda_{0}$ to $\lambda_{4}$ yield the short-run speed of adjustment for respective indicators and $\eta$ captures the speed of adjustment towards long-run equilibrium relationship.

\subsection{Multicollinearity Detection}

To guarantee reliable estimation and alleviate the chances of spurious regression, the study employed a Variance inflation factor (VIF). The VIF measures the individual value subject to the interdependence with others with the help of the following equation;

$$
V I F=\frac{1}{1-R^{2}}
$$

If VIF value outstrips five (VIF > 5), this demonstrates an intolerable level of interdependence of that independent variable, if continued, may yield spurious estimation. 


\subsection{Vector Error Correction Granger Causality}

The ARDL approach only suggests the existence of long-run association between given variables, hence does not provide the direction. Therefore, we need to test the direction of causality between the indicators of economic development, the exchange rate, and international tourism. Engle and Granger (1987) state that at least one unidirectional causality should exist between the variables that are integrated with the unique order of integration. Hence, we use VECM-Granger causality to identify the short and long-term causal flow between variables, which serves as an important input in the comprehensive policy formulation process. The VECM Granger causality is modeled using the following equation:

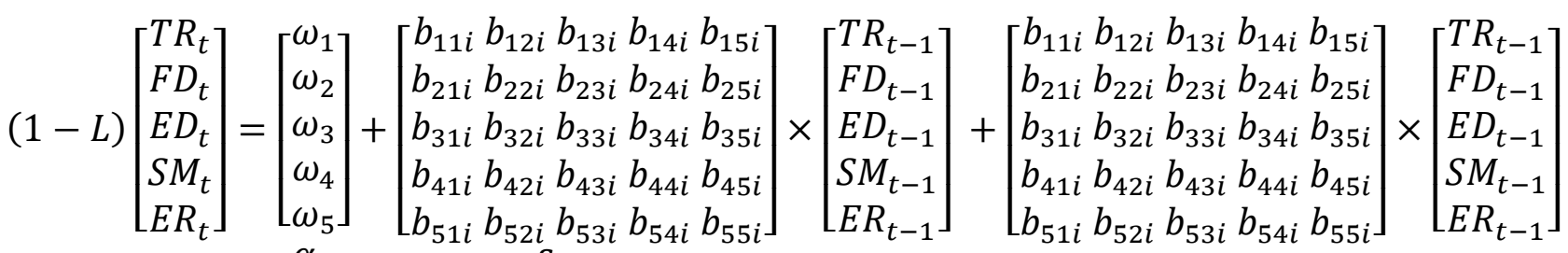

$$
\begin{aligned}
& +\left[\begin{array}{l}
\alpha \\
\beta \\
\gamma \\
\delta \\
\varphi
\end{array}\right] E_{t-1}+\left[\begin{array}{l}
\varepsilon_{1 t} \\
\varepsilon_{2 t} \\
\varepsilon_{3 t} \\
\varepsilon_{4 t} \\
\varepsilon_{5 t}
\end{array}\right]
\end{aligned}
$$

Where $(1-L)$ is difference operator, $E C M_{t-1}$ is the lagged error correction-term obtained from the long-term equation. The statistically significant value with a negative coefficient $E C M_{t-1}$ confirms the existence of a long-term causality. The short-term causal relationship depends on the first differences in the variables when relevant test statistics are significant.

\section{Results and Discussion}

This section the empirical results are discussed.

Table 1 shows the descriptive characteristics of the variables regarding a number of observations, mean, maximum, and minimum value. Standard deviation indicates the deviation from the central value, while Jarque-Bera captures the normality of the series. The series fulfills the normality condition when the corresponding probability value exceeds $5 \%$ benchmark. Overall, descriptive properties are satisfactory for further estimation.

Table 1: Descriptive Properties of Data

\begin{tabular}{|l|l|l|l|l|l|l|l|}
\hline & Observations & Mean & Max. & Min. & SD & Jarque-Bera & $p$-value \\
\hline LnTR1 & 28 & 13.335 & 13.965 & 12.819 & 0.410 & 3.336 & 0.189 \\
\hline LnTR2 & 28 & 20.407 & 20.843 & 20.014 & 0.260 & 3.213 & 0.201 \\
\hline FD & 28 & 22.637 & 28.736 & 15.386 & 4.139 & 1.603 & 0.449 \\
\hline ED & 28 & 941.234 & 1222.524 & 741.801 & 140.412 & 2.156 & 0.340 \\
\hline SM & 28 & 22.679 & 46.537 & 6.781 & 10.434 & 2.674 & 0.263 \\
\hline ER & 28 & 62.045 & 105.455 & 21.707 & 27.371 & 1.787 & 0.409 \\
\hline
\end{tabular}

Determination of integration order is an essential requirement for reliable estimation. Table 2 reports ADF results for the stationary condition. Other than ED, and ER rest of all variables are nonstationary at level $[\mathrm{I}(\mathrm{O})]$, as corresponding t-statistics is less than Dickey-Fuller critical value at $5 \%$ significance level, however, refer to $1^{\text {st }}$ difference $[\mathrm{I}(1)] \mathrm{TR} 1, \mathrm{TR} 2, \mathrm{FD}$, and SM satisfy the stationarity 
condition as t-statistics is greater than DF critical value. Therefore, the choice is ARDL is suitable for estimation particularly for this mixed integration order.

Table 2: Augmented Dickey-Fuller test statistic for stationary

\begin{tabular}{|l|l|l|l|l|}
\hline \multicolumn{3}{|l|}{ At level } & \multicolumn{2}{l|}{ At ${ }^{\text {st }}$ difference } \\
\hline Variable & t-stat & C.V $(5 \%)$ & t-stat & C.V (5\%) \\
\hline TR1 & -2.128 & -3.587 & $-4.903^{* * *}$ & -3.595 \\
\hline TR2 & -2.121 & -3.468 & $-3.468^{* *}$ & -3.120 \\
\hline FD & -2.565 & -2.898 & $-3.467^{* *}$ & -3.465 \\
\hline ED & $-2.898^{* *}$ & -2.540 & $-3.463^{* *}$ & -3.277 \\
\hline SM & -1.832 & -2.902 & $-2.902^{* *}$ & -2.877 \\
\hline ER & $-3.719^{* *}$ & -3.622 & $-3.539^{* *}$ & -3.223 \\
\hline
\end{tabular}

$\left(^{*}\right)$ and $\left(^{* *}\right)$ Indicates p-value significant at 5\% and $1 \%$. Null Hypothesis: "Variable has unit root / data in not stationary”. Criteria: If p-value ( $<0.05 \sim$ t-stat $>$ critical value at $5 \%$ significance level) the hypothesis is rejected, otherwise accepted.

Table 3 shows the ARDL Bounds test output for model-1 and 2. According to the ARDL Bounds test, a long-run relationship exists among variables, when the F-stat value exceeds the upper bound value for a chosen level of significance. In this table, at 5\% confidence interval F-stat value for model-1 (3.92) is greater than critical upper bound value at 5\% and $1 \%$ level of significance, and for model-2 at all three levels of significance that reveals a long run relationship among TR and set of predictors (FD, ED, SM, and ER). Therefore, we reject the null hypothesis of no cointegration and accept the alternative, which holds the existence of cointegration. This implies that economic development, exchange rate, and international tourism are having a long-run association.

Table 3: ARDL Bounds Test for Long Run Relationship

\begin{tabular}{|c|c|c|c|c|}
\hline F-Statistic & Value & \multicolumn{3}{|c|}{ Critical Value Bounds } \\
\hline \multirow{3}{*}{ Model-1(TR1) } & \multirow{2}{*}{$3.92^{* *}$} & Significance & Io Bound & I1 Bound \\
\hline & & $10 \%$ & 2.20 & 3.09 \\
\hline & & $5 \%$ & 2.56 & 3.49 \\
\hline Model-1(TR2) & $4.65^{* * *}$ & $1 \%$ & 3.29 & $4 \cdot 37$ \\
\hline
\end{tabular}

$\left.(*),{ }^{* *}\right)$ denotes significance at $5 \%$ and $1 \%$ level respectively. Null Hypothesis: No long-run relationships exist. The long-run relationship holds when F-stat exceeds upper bound at the chosen significance level.

Table 4 presents some important attributes of ARDL Bounds testing model and long-run dynamics concerning both models. In the first portion demonstrates the long-run coefficients adjusted R-square and F-statistics, while the second portion of this table shows the diagnostic properties of the estimators. Adjusted R-square for both models are reasonable in explaining the prediction power that shows that model-1 predicts 96\% variation in tourism, and model-2 explains 93\%. The individual coefficients of all indicators of ED show a positive and significant association with TR. This implies that 
ED is a long-run source that attracts the international tourists to visit memorial places of Pakistan.

Interestingly we find that exchange rate is vital in attracting the inward tourism in Pakistan over long-run. Significant F-statistics advocates that the relevant variables are considered for estimation. The second part of Table 4 illustrates the diagnostics and stability features of the estimators such as serial correlation, heteroscedasticity, Ramsey RESET, and CUSUM statistics respectively. All diagnostics testing reveals that the estimators are free from serial correlation, and heteroscedasticity, and Ramsey RESET and CUSUM statistics confirm the stability condition of the estimators. The CUSUM and CUSUM Square for stability are tested based on the following hypothesis. Null Hypothesis: Parameters are stable. Criteria: If blue lines lie between two red lines, we accept the null hypothesis, otherwise accept the alternative. Therefore, the graphical depiction in Figures 1-4 (appendix), shows that the blue line moves between two red lines for both CUSUM test and CUSUM Square tests, ensures the stable and systematic movement of predictors over the study period. Thus, our parameters fulfill stability conditions.

Table 4: ARDL long-run dynamics and diagnostics

\begin{tabular}{|c|c|c|}
\hline \multicolumn{3}{|l|}{ ARDL Long-run } \\
\hline & Model (1) & Model (2) \\
\hline Variable & TR1 & TR2 \\
\hline \multirow[t]{2}{*}{ FD } & $0.199^{* * *}$ & $0.108^{* * *}$ \\
\hline & $(3.21)$ & $(2.50)$ \\
\hline \multirow[t]{2}{*}{$\mathrm{ED}$} & $0.299^{* * *}$ & $0.297^{* * *}$ \\
\hline & $(3.19)$ & $(3.49)$ \\
\hline \multirow[t]{2}{*}{ SM } & $0.117^{* *}$ & 0.074 \\
\hline & $(2.15)$ & $(0.42)$ \\
\hline \multirow[t]{2}{*}{ ER } & $0.179^{* * *}$ & $0.372^{\star * *}$ \\
\hline & $(4 \cdot 39)$ & $(4 \cdot 38)$ \\
\hline \multirow[t]{2}{*}{$\mathrm{C}$} & $3.587^{* * *}$ & $2.298^{* * *}$ \\
\hline & $(7.38)$ & $(5.34)$ \\
\hline Adjusted R-squared & 0.959 & 0.934 \\
\hline \multirow{2}{*}{ F-statistics } & 66.253 & 40.361 \\
\hline & [0.00o] & {$[0.000]$} \\
\hline \multicolumn{3}{|l|}{ Diagnostic and stability testing } \\
\hline \multirow[t]{2}{*}{$\begin{array}{l}\text { LM test of the Breusch-Godfrey series } \\
\text { correlation: }\end{array}$} & 0.941 & 0.970 \\
\hline & {$[0.415]$} & {$[0.403]$} \\
\hline \multirow[t]{2}{*}{$\begin{array}{l}\text { Heteroscedasticity Test: Breusch-Pagan- } \\
\text { Godfrey }\end{array}$} & 0.693 & 1.045 \\
\hline & {$[0.718]$} & {$[0.449]$} \\
\hline \multirow[t]{2}{*}{ Ramsey RESET Test } & 0.820 & 0.670 \\
\hline & {$[0.426]$} & {$[0.513]$} \\
\hline CUSUM Test & \multicolumn{2}{|l|}{ Stable } \\
\hline CUSUM Square Test & Stable & \\
\hline \multicolumn{3}{|c|}{$\begin{array}{l}\text { Note: }\left({ }^{* *}\right)\left({ }^{* *}\right) \text { and }\left({ }^{*}\right) \text { indicate significance at } 1 \%, 5 \% \text { and } 10 \% \\
\text { respectively. Robust t-stat is in parenthesis. Numbers in quads are p- } \\
\text { values with respect to related statistics. }\end{array}$} \\
\hline
\end{tabular}


The ECM confirms the long-term association between variables identified by the ARDL Bounds test. For a long-term equilibrium relationship, it is essential that the sign of the error correction term be negative and statically significant. Table 5 shows that the coefficient for ECM is negative and predicts that the system corrects the imbalance of the previous period with an annual adjustment rate of $42 \%$ and 32\%, respectively, for each model. Similarly, economic development indicators have proven to be positive in the short term and are a major contributor to tourism in Pakistan. The exchange rate has a negative impact on tourism in the country; this is likely due to the devaluation of the local currency against the US dollar.

Table 5: Short-run dynamics and speed of adjustment

\begin{tabular}{|l|l|l|l|}
\hline & Model-1 & \multicolumn{1}{|c|}{ Model-2 } \\
\hline$\Delta \mathrm{FD}_{\mathrm{t}}$ & $0.229^{* * *}$ & $0.189^{* * *}$ \\
\hline$\Delta \mathrm{ED}_{\mathrm{t}}$ & $(3.26)$ & $(2.5 \mathrm{O})$ \\
\hline & $0.120^{*}$ & $0.17 \mathrm{O}^{* * *}$ \\
\hline$\Delta \mathrm{SM}_{\mathrm{t}}$ & $(1.82)$ & $(4.36)$ \\
\hline & $0.145^{* * *}$ & $0.056^{* * *}$ \\
\hline$\Delta \mathrm{ER}_{\mathrm{t}}$ & $(2.52)$ & $(3.78)$ \\
\hline & $-0.134^{* * *}$ & $-0.103^{* * *}$ \\
\hline $\mathrm{ECM}_{\mathrm{t}-1}$ & $(-2.85)$ & $(-2.88)$ \\
\hline & - & - \\
\hline $\begin{array}{l}\text { Note: }\left(^{* * *}\right)\left(^{* *}\right) \text { and }\left({ }^{*}\right) \text { indicate the significance at } 1 \%, 5 \%, \\
\text { respectively. Robust T-stat is in parentheses. The sign of } \mathrm{ECM} \\
\text { coefficients should be negative and statistically significant to ensure } \\
\text { long-term association between variables. }\end{array}$ \\
\hline
\end{tabular}

Table 6 portrays the collinearity results captured through the variance inflation factor (VIF). If the calculated value of VIF is less than 5, the concerned predictor is considered to be free from collinearity problem. VIF for FD (3.590), ED (2.706), SM (3.003) and ER (3.1) is less than five. Thus consequent estimation is not suffering from collinearity problem.

Table 6: Variance Inflation Factor

\begin{tabular}{|l|l|l|}
\hline Variable & Variance & VIF \\
\hline FD & 0.009 & 3.590 \\
\hline ED & 0.004 & 2.706 \\
\hline SM & 0.002 & 3.004 \\
\hline ER & 0.005 & 3.100 \\
\hline $\begin{array}{l}\text { Note: VIF value should be less than 5, and if holds, the } \\
\text { predictors are not having multicollinearity problem. }\end{array}$ \\
\hline
\end{tabular}

Table 7 reports the VECM Granger causality results of the reference variables. The sources of causation are divided into short-run and long-run. A left designated portion of the table shows the short-run causal flow for each pair of variables, and the rightmost column shows the long-run attribute. We find that there exists a bidirectional causal flow between; FD - TR, ED- TR, ER- TR, FD-SM, 
FD-ED, ED-ER, SM-ER and a unidirectional causal flow from ER-FD. This implies that the parameters estimated in this study are worthwhile for immediate policy actions. About the long-run VECM Granger Causality affirms the findings of ARDL bounds test and ECM as to the cointegration between TR, FD, $\mathrm{ED}, \mathrm{SD}$, and ER. The findings suggest that these variables are equally important in short-run and longrun. The policymakers need to understand the dynamic nature of this association for effective policy formulation.

Table 7: VECM Granger Causality Results

\begin{tabular}{|c|c|c|c|c|c|c|}
\hline & & & So & rces of & Causatio & \\
\hline $\begin{array}{l}\text { Depen } \\
\text { variab }\end{array}$ & & Short-F & un & & & Long-Run \\
\hline & $\Delta \mathrm{TR}_{\mathrm{t}}$ & $\Delta \mathrm{FD}_{\mathrm{t}}$ & $\Delta \mathrm{ED}_{\mathrm{t}}$ & $\begin{array}{l}\Delta \mathrm{SM} \\
\mathrm{t}\end{array}$ & $\Delta \mathrm{ER}_{\mathrm{t}}$ & $\mathrm{ECM}_{\mathrm{t}-1}$ \\
\hline$\Delta \mathrm{TR}_{\mathrm{t}}$ & - & $2.71^{* *}$ & $\begin{array}{l}6.16^{* *} \\
*\end{array}$ & 0.34 & $2.934^{\star *}$ & $-8.15^{* *}$ \\
\hline & - & 0.042 & 0.001 & $\begin{array}{l}0.84 \\
4\end{array}$ & 0.023 & 0.023 \\
\hline$\Delta \mathrm{FD}_{\mathrm{t}}$ & $7.09 * *$ & - & $2.85^{* *}$ & 0.77 & 2.695 & $-22.56 * * *$ \\
\hline & 0.029 & - & 0.024 & $\begin{array}{l}0.67 \\
9\end{array}$ & 0.260 & 0.004 \\
\hline$\Delta \mathrm{ED}_{\mathrm{t}}$ & $6.86^{* *}$ & 1.38 & - & 3.81 & $5 \cdot 382$ * & $-16.55^{* *}$ \\
\hline & 0.032 & 0.503 & - & $\begin{array}{l}0.14 \\
9\end{array}$ & 0.068 & 0.035 \\
\hline$\Delta \mathrm{SM}_{\mathrm{t}}$ & 1.72 & $5 \cdot 35^{*}$ & $5.64^{* *}$ & - & $5 \cdot 515^{*}$ & $-7.60 * *$ \\
\hline & 0.424 & 0.069 & 0.044 & - & 0.064 & 0.042 \\
\hline$\Delta \mathrm{ER}_{\mathrm{t}}$ & $4 \cdot 42^{*}$ & $\begin{array}{l}7 \cdot 57^{*} \\
*\end{array}$ & $6.94^{* *}$ & $\begin{array}{l}4.69 \\
*\end{array}$ & - & $-14.21^{*}$ \\
\hline & 0.092 & 0.023 & 0.031 & $\begin{array}{l}0.09 \\
6\end{array}$ & - & 0.077 \\
\hline $\begin{array}{l}\text { Note: } \\
10 \%, \\
\text { reject }\end{array}$ & $\begin{array}{l}(* *) \\
\text { ectively } \\
\text { hile nu }\end{array}$ & $\begin{array}{l}(*) \text { ir } \\
\text { t whic }\end{array}$ & $\begin{array}{l}\text { licate } \\
\text { null } \\
\text { centhe }\end{array}$ & $\begin{array}{l}\text { signi } \\
\text { pothe } \\
\text { are co }\end{array}$ & $\begin{array}{l}\text { cance a } \\
\text { s for } 1 \\
\text { respond }\end{array}$ & $\begin{array}{l}\%, 5 \% \text {, anc } \\
\text { causation is } \\
\text { p-values. }\end{array}$ \\
\hline
\end{tabular}

\section{Conclusion}

This study examines how economic development is attracts the international tourism in the context of Pakistan. The study uses ARDL testing for long-term relationship, the ECM for a short-term relationship, and VECM Granger causality to determine the direction of causal flow. The study uses annual time-series data from the CEIC and World Bank databases for the period 1990-2017. We find that the ARDL model used is free of serial correlation and heteroscedasticity and satisfies the stability condition. Empirical evidence documents that there is a long-run connection between economic development and international tourism in Pakistan. In particular, the revenues received from international tourists can be used for the economic well-being of a country in general and the tourism department in particular. According to Khalil et al. (2007), there is a strong relationship among tourist receipts, the number of arrivals and economic expansion. At the other edge of the spectrum, ED of a country attracts international tourists, facilitated by the widespread financial sector, and inspired by a wide range of well-developed parks, viewpoints and more importantly natural beauty in North belt of 


\section{Review of Economics and Development Studies, Vol. 6 (2) 2020, 229-244}

Pakistan, and Kashmir. A reasonable amount of literature is found on the impact of tourism revenues on ED - yet the studies are rare in context of emerging markets such as Pakistan. This paper examines cointegration between ED and TR, using the robust Bounds testing approach and VECM Granger Causality. Novelty stems from the perspective that there is no formal evidence found on cointegration between ED and TR from Pakistan.

This research is a pioneering effort that examines the cointegration between ED measures such as domestic credit, per capita GDP, market capitalization and their long-run association with tourism revenue and a number of arrivals in Pakistan. The study takes into account only Pakistan to test the long-run relationship of ED and TR. Nevertheless, it contributes to the existing literature on this vital phenomenon. In addition, it offers policy implications to focus on three economic dimensions; economic development, financial development, and stock market development, which subsequently attracts international tourism. Moreover, an intuitive sense, it promulgates National culture and image across national borders and strengthens the National Treasury as well. Tourism improves the standard of living (Hrubcova et al., 2016). Pakistan tourism department needs to revisit the policies to offer a more lucrative and amiable environment to international tourists. In line with the findings of Milne and Ateljevic (2001), media should play its pivotal role more effectively to promotion National culture and core tourists' hubs that will in turn lead towards economic development and sound image of Pakistan worldwide.

\section{References}

Akama, J. S., \& Kieti, D. (2007). Tourism and socio-economic development in developing countries: A case study of Mombasa Resort in Kenya. Journal of sustainable tourism, 15(6), 735-748.

Antonakakis, N., Dragouni, M., Eeckels, B., \& Filis, G. (2016). Tourism and economic growth: Does democracy matter? Annals of Tourism Research, 61(C), 258-264.

Azeem, A., Aziz, B., \& Jadoon, A. K. (2015). Financial Development: A Contributing Agent of Economic Growth-Study of Selected Asian Countries. Pakistan Business Review, 17(2), 397-415.

Balaguer, J., \& Cantavella-Jorda, M. (2002). Tourism as a long-run economic growth factor: the Spanish case. Applied economics, 34(7), 877-884.

Breitung, J. (2001). The local power of some unit root tests for panel data Nonstationary panels, panel cointegration, and dynamic panels (pp. 161-177): Emerald Group Publishing Limited.

Culiuc, M. A. (2014). Determinants of international tourism: International Monetary Fund.

Dickey, D. A., \& Fuller, W. A. (1979). Distribution of the Estimators for Autoregressive Time Series with a Unit Root. Journal of the American Statistical Association, 74(366a), 427-431. doi: 10.1080/01621459.1979.10482531

Dickey, D. A., \& Fuller, W. A. (1981). Likelihood Ratio Statistics for Autoregressive Time Series with a Unit Root. Econometrica, 49(4), 1057-1072. doi: 10.2307/1912517

Dritsakis, N. (2004). Cointegration analysis of German and British tourism demand for Greece. Tourism Management, 25(1), 111-119.

Du, D., Lew, A. A., \& Ng, P. T. (2016). Tourism and economic growth. Journal of Travel Research, 55(4), 454-464.

Engle, R. F., \& Granger, C. W. (1987). Co-integration and error correction: representation, estimation, and testing. Econometrica: journal of the Econometric Society, 251-276.

Faber, B., \& Gaubert, C. (2016). Tourism and Economic Development: Evidence from Mexico's 


\section{Review of Economics and Development Studies, Vol. 6 (2) 2020, 229-244}

Coastline: National Bureau of Economic Research.

Haug, A. A. (2002). Temporal aggregation and the power of cointegration tests: a Monte Carlo study. Oxford Bulletin of Economics and Statistics, 64(4), 399-412.

Hrubcova, G., Loster, T., \& Obergruber, P. (2016). The Economic Effects of Tourism in the Group of the Least Developed Countries. Procedia Economics and Finance, 39, 476-481. doi: http://dx.doi.org/10.1016/S2212-5671(16)30351-3

Hye, A. Q. M., \& Khan, A. R. E. (2013). Tourism-led growth hypothesis: a case study of Pakistan. Asia Pacific Journal of Tourism Research, 18(4), 303-313.

Jebran, K., Abdullah, A., Iqbal, A., \& Ullah, I. (2016). Effects of remittances on per capita economic growth of Pakistan. Pakistan Business Review, 18(1), 1-18.

Johansen, S. (1991). Estimation and hypothesis testing of cointegration vectors in Gaussian vector autoregressive models. Econometrica: Journal of the Econometric Society, 1551-1580.

Kennell, J. (2016). Tourism and economic development in Suffolk.

Khalil, S., Kakar, M. K., \& Malik, A. (2007). Role of Tourism in Economic Growth: Empirical Evidence from Pakistan Economy [with Comments]. The Pakistan Development Review, 985-995.

Liu, Z. (2003). Sustainable tourism development: A critique. Journal of sustainable tourism, 11(6), 459475 .

MacKinnon, J. G., Haug, A. A., \& Michelis, L. (1999). Numerical distribution functions of likelihood ratio tests for cointegration. Journal of applied econometrics, 563-577.

Malik, S., Chaudhry, I. S., Sheikh, M. R., \& Farooqi, F. S. (2010). Tourism, economic growth and current account deficit in Pakistan: Evidence from co-integration and causal analysis. European Journal of Economics, Finance and Administrative Sciences, 22, 21-31.

Milne, S., \& Ateljevic, I. (2001). Tourism, economic development and the global-local nexus: theory embracing complexity. Tourism geographies, 3(4), 369-393.

Pesaran, M. H., \& Shin, Y. (1998). An autoregressive distributed-lag modelling approach to cointegration analysis. Econometric Society Monographs, 31, 371-413.

Pesaran, M. H., Shin, Y., \& Smith, R. J. (2001). Bounds testing approaches to the analysis of level relationships. Journal of applied econometrics, 16(3), 289-326.

Qian, C., Sasaki, N., Shivakoti, G., \& Zhang, Y. (2016). Effective governance in tourism development An analysis of local perception in the Huangshan mountain area. Tourism Management Perspectives, 20, 112-123. doi: http://dx.doi.org/10.1016/j.tmp.2016.08.003

Sequeira, T. N., \& Macas Nunes, P. (2008). Does tourism influence economic growth? A dynamic panel data approach. Applied economics, 40(18), 2431-2441.

Sharif, A., \& Raza, S. A. (2016). Dynamic relationship between urbanization, energy consumption and environmental degradation in Pakistan: Evidence from structure break testing. Journal of Management Sciences, 3(1), 01-21.

Sinclair, M. T. (1998). Tourism and economic development: A survey. The journal of development studies, 34(5), 1-51.

Srinivasan, P., \& Kalaivani, M. (2016). Tourism Expansion and Economic Growth in Asia-Pacific Nations: A Panel Causality Approach.

Ullah, Z., \& Wizarat, S. (2016). Long term relationship between stock market development and 
economic growth in south asia: Panel data \& ardl model estimations. Pakistan Business Review, 18(3), 541-557.

WEF. (2017). Global Competitiveness Report World Economic Forum, New York: USA Inc.

Zhang, L., \& Gao, J. (2016). Exploring the effects of international tourism on China's economic growth, energy consumption and environmental pollution: Evidence from a regional panel analysis. Renewable and Sustainable Energy Reviews, 53, 225-234. 


\section{Appendices}

Figure 1. CUSUM Test (model-1)

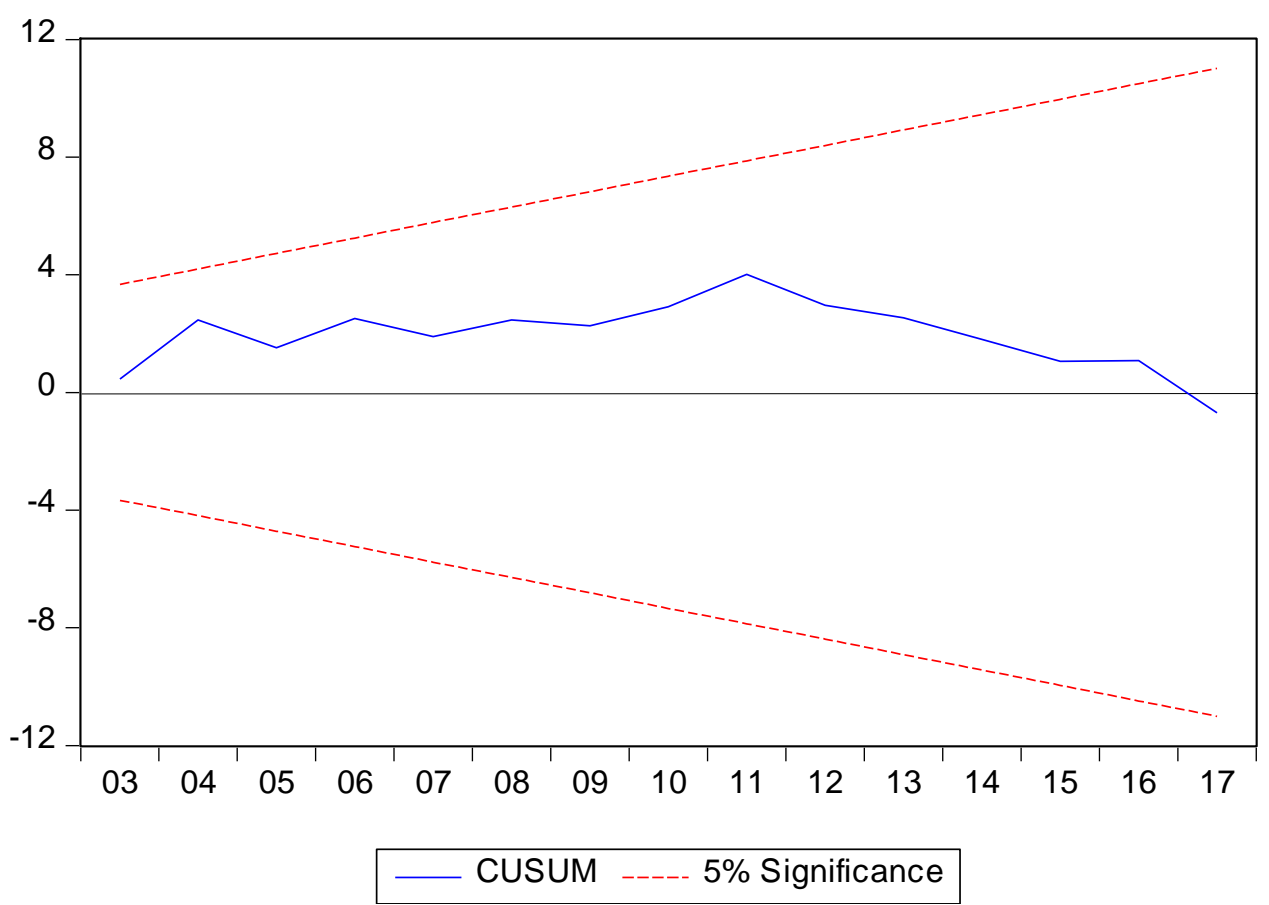

Figure 2. CUSUM Square test (model-1)

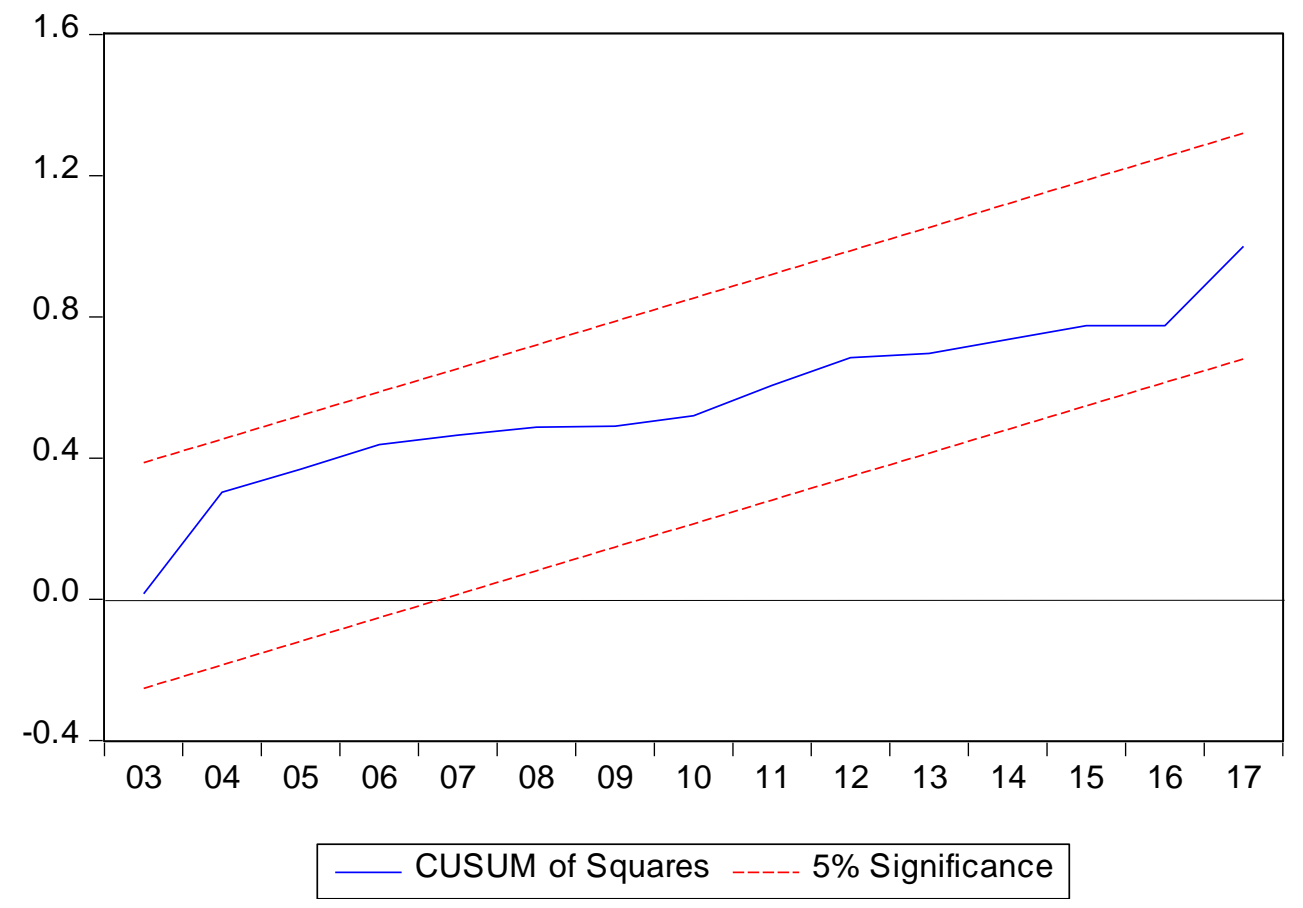


Figure 3. CUSUM Test (model-2)

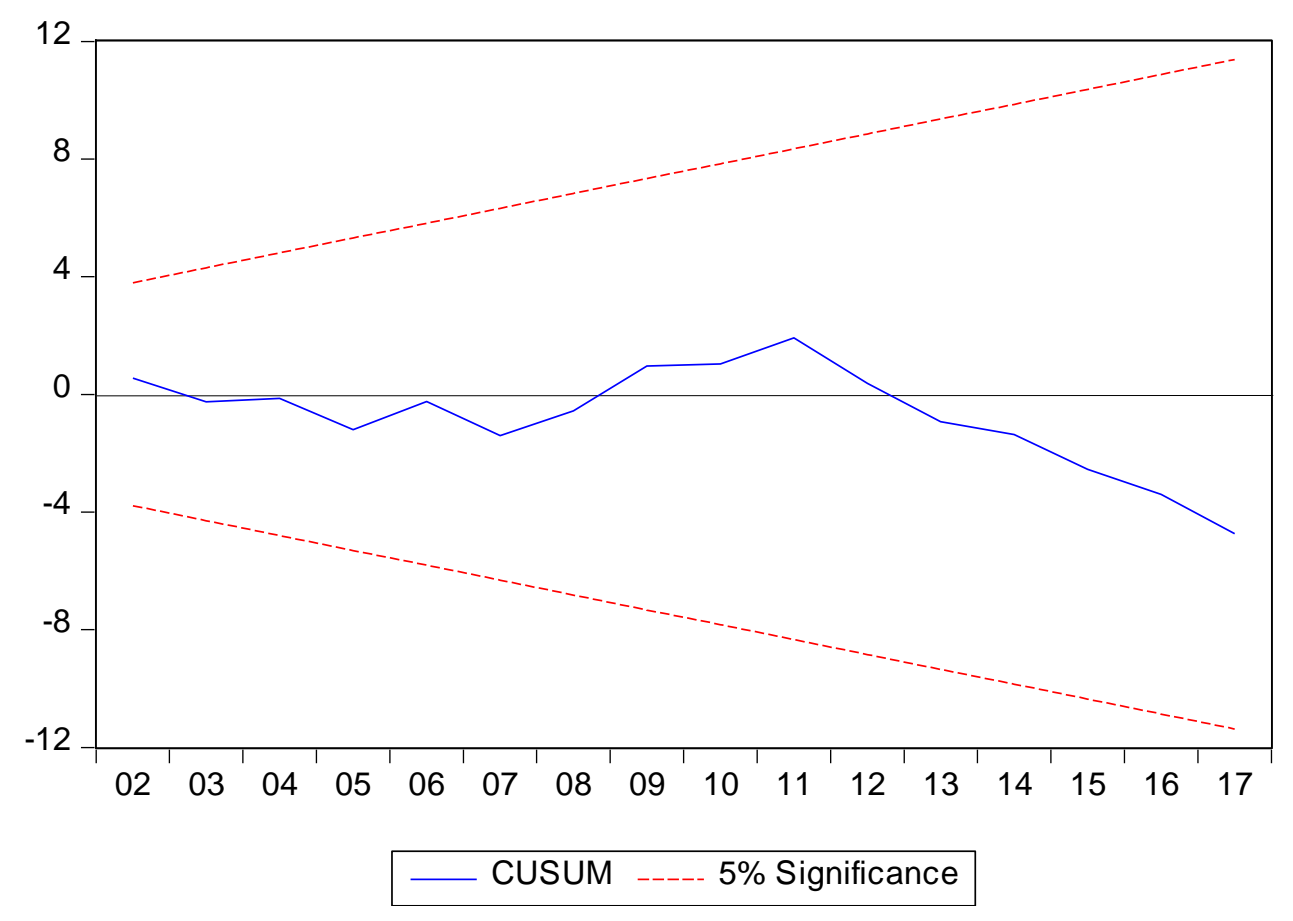

Figure 4. CUSUM Square test (model-2)

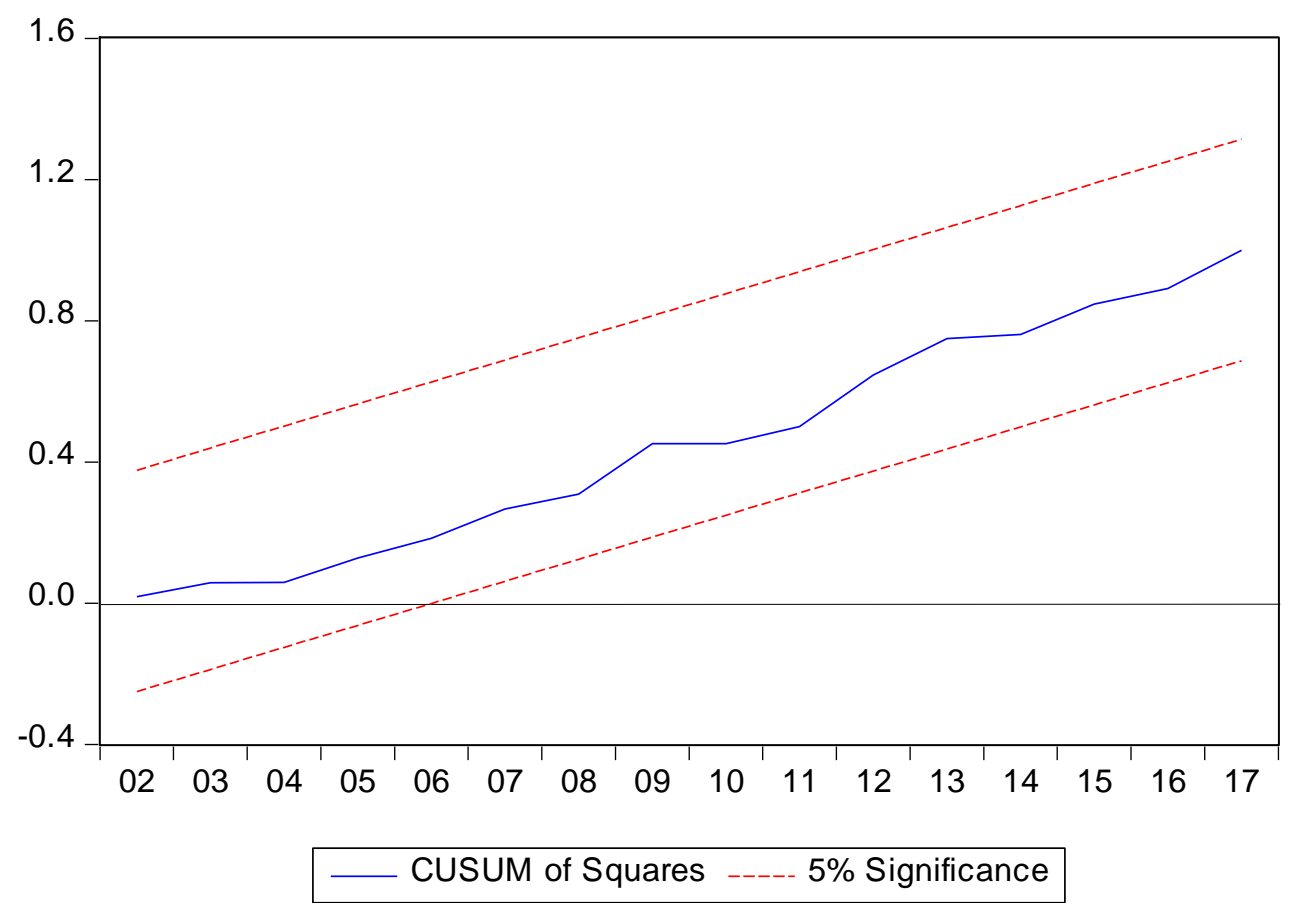

